\title{
Thyroid Primary Schwannoma
}

Sofia Guerreiro*, Cristina Ribeiro, Henrique Candeias, Matilde Gonçalves, Rosário Eusébio and Luís Cortez

Department of General Surgery, Hospital de São Bernardo, Centro Hospitalar de Setúbal, E.P.E., Setúbal, Portugal

*Corresponding author: Sofia Guerreiro, Department of General Surgery, Hospital de São Bernardo, Centro Hospitalar de Setúbal, E.P.E., Setúbal, Portugal, Tel: +351265549000; E-mail: sofiacuco@gmail.com

Received date: Sep 26, 2015, Accepted date: Oct 09, 2015; Published date: Oct 11, 2015

Copyright: @ 2015 Guerreiro S, et al. This is an open-access article distributed under the terms of the Creative Commons Attribution License, which permits unrestricted use, distribution, and reproduction in any medium, provided the original author and source are credited.

\begin{abstract}
Thyroid gland is a very rare location of non-epithelial tumors (less than $1 \%$ of all thyroid tumors) and particularly schwannomas. Only 19 cases have been published in English literature until today. Approximately $25 \%$ of schwannomas occur in the head and neck region, most of them in relation to peripheral nerves and to cervical sympathetic chain.
\end{abstract}

We present a case with clinical and sonographic features of a benign thyroid nodule. The diagnosis of schwannoma was established after definitive histopathologic evaluation.

With this article we intend to review clinical, radiological and pathological changes associated with this tumor, emphasizing the difficulty in making a preoperative diagnosis.

Keywords: Schwannoma; Thyroid gland; Histopathologic evaluation

\section{Introduction}

Schwannomas were first described in 1908 by Verocay and its location within the thyroid gland is extremely rare. They mimic a thyroid nodule and its sonographic and citological features make preoperative diagnosis a challenge.

Schwannoma (also called neuromas, or neurilemoma) is a benign and slow growing tumour originated in schwann cells. These are derived from the neural tube and are part of the glial cells which main function is to form the myelin sheath, acting as electrical insulators and contributing to a better conduction of nerve stimuli. The schwannoma can occur at any myelinated nerve fibre, anywhere in the body, although more than $25 \%$ originates from head and neck $[1,2]$.

\section{Clinical Case}

A 26 year old man was referred to the Endocrine Surgery Unit in Centro Hospitalar de Setúbal because of an increased cervical mass that was first noted 12 months before and had progressively grown. The patient reported mild compressive symptoms but otherwise was asymptomatic. On physical examination, a mobile and nontender firm node, approximately $3 \mathrm{~cm}$ wide, was noted in the right thyroid region, with no lymphadenopathy found.

Laboratory studies showed normal TSH $(1,25 \mathrm{uUI} / \mathrm{ml})$, fT4 $(1,16$ $\mathrm{ng} / \mathrm{dL})$, calcium $(9,4 \mathrm{mg} / \mathrm{dL})$ and phosphorus $(3,80 \mathrm{mg} / \mathrm{dL})$.

The ultrasonography identified a hypodense well-delineated thyroid nodule with no calcifications, a full halo and type II vascularization on the middle third of the right lobe that measured $26.7 \times 27.5 \times 31.9$ $\mathrm{mm}$.

After three attempts of fine-needle aspiration ultrasound guided, we couldn't obtain a cytological characterization: abundant blood, some stromal cells and scarce epithelial cells, scarce colloid. Considering the symptoms and the inability to achieve cytological results we proposed the patient for operative treatment, which he accepted.

A right lobectomy with isthmectomy was performed with an extemporaneous examination that did not reveal the presence of neoplastic cells.

The patient had a normal and uneventful postoperative course, and was discharged on the first day after surgery.

Definitive histological examination of the surgical specimen showed a well encapsulated mass of long and spindle-shaped cells. Immunohistochemistry revealed strong positivity for S-100 protein and vimentin, consistent with Schwannoma (Figures 1-4).

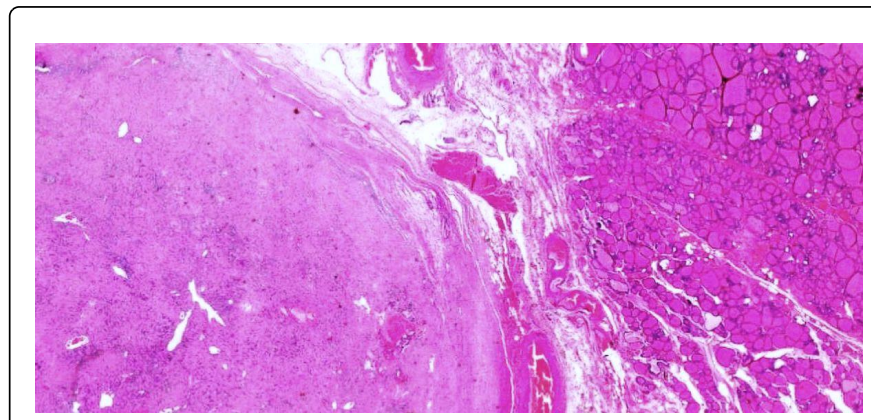

Figure 1: The tumour appears very well encapsulated and is sharply demarcated from the adjacent thyroid tissue (H\&E).

\section{Discussion}

Nonepithelial tumours of the thyroid gland are rare. Schwannomas arise from neuronal sheath cells (schwan cells). They are rare, solitary, encapsulated, slow-growing tumours and rarely exhibit malignant transformation $[1,3]$. 


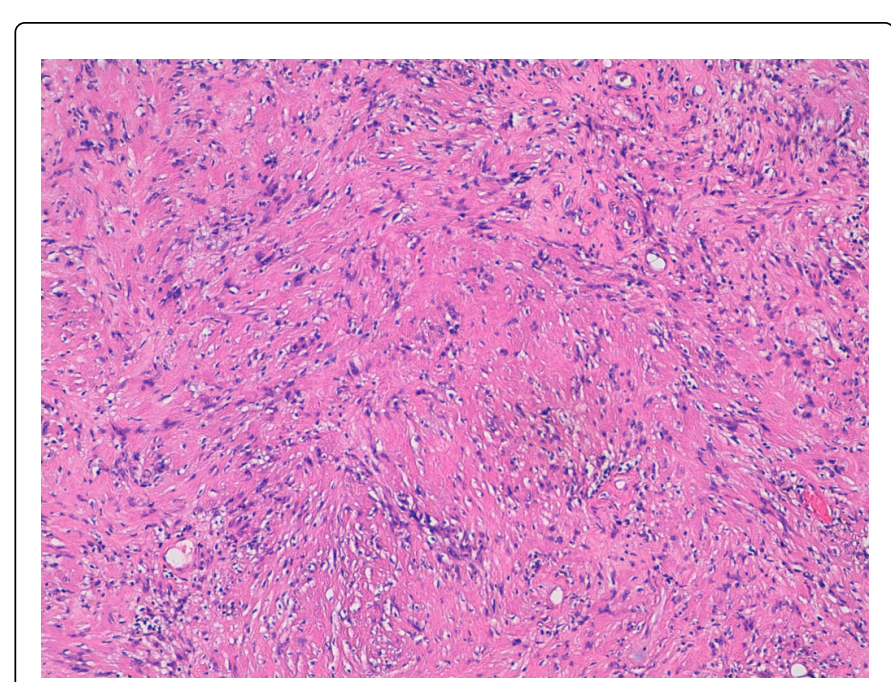

Figure 2: Schwannoma (H\&E).

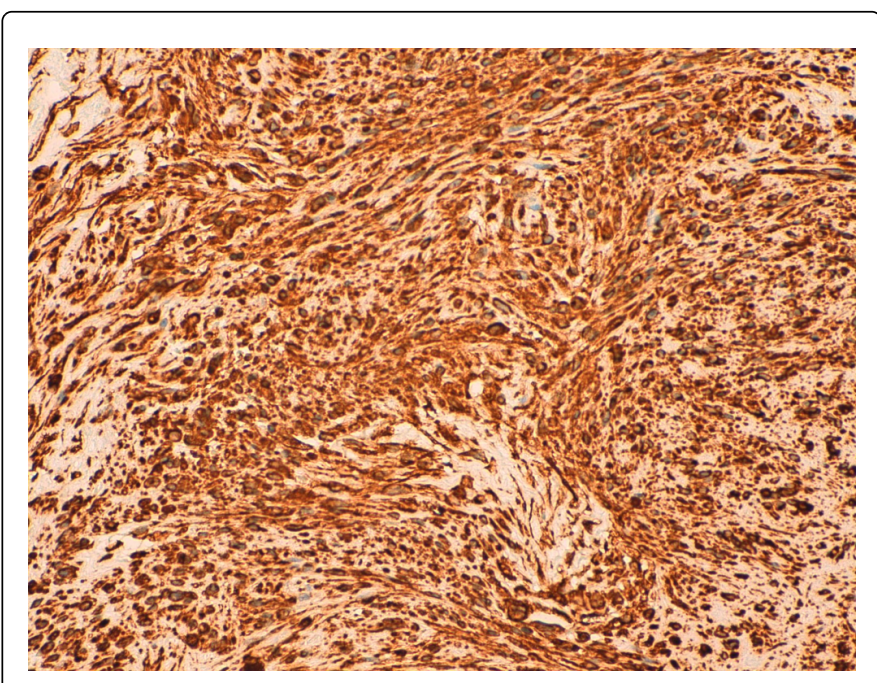

Figure 3: Schwannoma. Imunohistochemical staining with vimentin.

It is very difficult to make a correct preoperative diagnosis. The first symptom may be the presence of a cervical mass in a euthyroid patient that compresses the surrounding structures as it grows. On ultrasound they are well defined, hypoechoic and without ganglion involvement. The CT scan reveals, most of the times, a well-circumscribed, homogeneous and nonspecific lesion.

Fine-needle aspiration is, in most cases, unsuccessful and does not allow obtaining an accurate diagnosis; a histological study with immunohistochemical techniques is frequently required.

Complete surgical excision is the technique of choice in the treatment of this pathology. Although an enucleation is generally sufficient, most of the times, like in this case, due to a difficult preoperative diagnosis, a lobectomy is necessary [4-7].

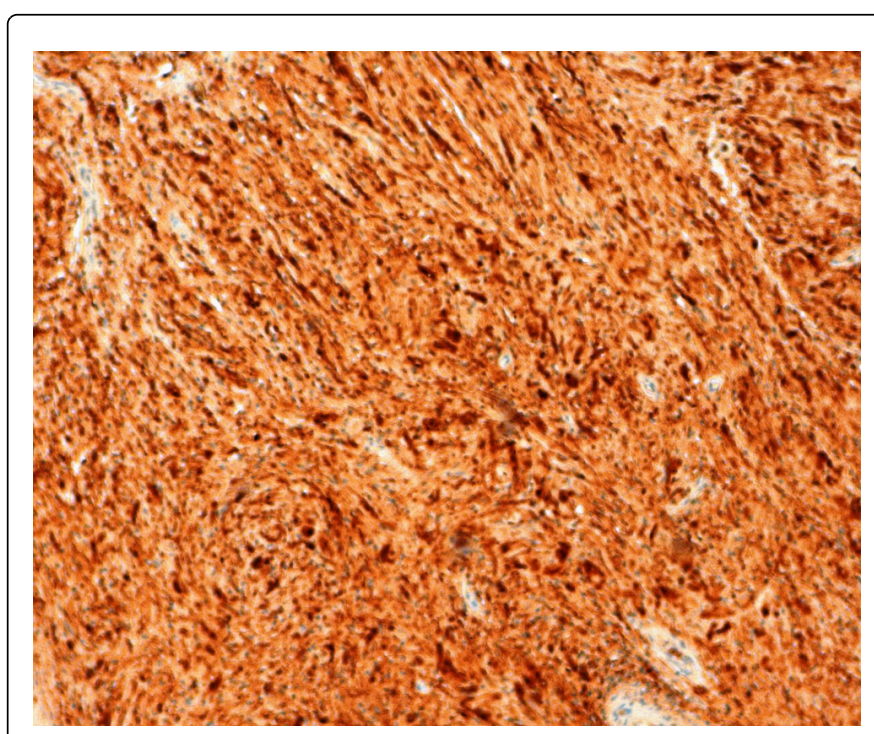

Figure 4: Schwannoma. Imunohistochemical staining with S-100 protein.

\section{Conclusion}

Although a rare entity, schwannoma and other non-epithelial tumours should be considered in the differential diagnosis of thyroid nodules. The complete surgical excision of the lesion is considered the treatment of choice.

\section{References}

1. Gamal WL, Abdel Khalek MS, Crawford BE, Kandil EH (2011) Hoarseness due to a thyroid mass. Symptomatic thyroid schwannoma. Neth J Med 69: 39-40.

2. Jong YN, Lee JJ, Chan YJ, Cheng SP (2012) Neurilemmoma of the thyroid gland. Intern Med 51: 1641.

3. Gustafson LM, Liu JH, Rutter MJ, Stern Y, Cotton RT (2001) Primary neurilemoma of the thyroid gland: a case report. Am J Otolaryngol 22: 84-86.

4. Kandil E, Abdel Khalek M, Abdullah O, Dali D, Faruqui S, et al. (2010) Primary peripheral nerve sheath tumors of the thyroid gland. Thyroid 20: 583-586.

5. Dhar H, Dabholkar JP, Kandalkar BM, Ghodke R (2014) Primary thyroid schwannoma masquerading as a thyroid nodule. J Surg Case Rep 2014.

6. De Paoli F, Giugliano G, Casadio C, Tredici P, Bruschini R, et al. (2005) Schwannoma of thyroid bed. A case report and considerations on interdisciplinary collaboration. Acta Otorhinolaryngol Ital 25: 250-252.

7. Mangal N, Agarwal AK, Sharma VK, Sharma SP (2010) Neurilemmoma (schwannoma) of the thyroid gland: a rare case presentation. Indian J Pathol Microbiol 53: 873-874. 